\title{
CHAMP Radio Occultation Detection of the Planetary Boundary Layer Top
}

\author{
Axel von Engeln ${ }^{1,2}$, João Teixeira ${ }^{3}$, Jens Wickert ${ }^{4}$, and Stefan A. Buehler ${ }^{2}$ \\ 1 Satellite Applications, Met Office, Exeter, United Kingdom \\ engeln@uni-bremen.de \\ 2 Institute of Environmental Physics, University of Bremen, Germany \\ sbuehler@uni-bremen.de \\ 3 UCAR/VSP at Marine Meteorology Division, Naval Research Laboratory, \\ Monterey, CA, USA teixeira@nrlmry.navy.mil \\ 4 Department 1 Geodesy and Remote Sensing, GeoForschungsZentrum Potsdam, \\ Potsdam, Germany wickert@gfz-potdsdam.de
}

Summary. A simple approach to derive the Planetary Boundary Layer (PBL) top altitude from the CHAllenging Mini-satellite Payload (CHAMP) radio occultation data is presented. The lowest sampled altitude is assumed to be determined by the top of the PBL. We average CHAMP measurements for the years 2002 and 2003 over 5 degree latitude longitude boxes and compare them to European Centre for Medium-range Weather Forecasts (ECMWF) data. The ECMWF PBL top was calculated from the relative humidity gradient with respect to altitude. The altitude where this gradient has its minimum and temperatures are above $273 \mathrm{~K}$ is assumed to represent the PBL top. Agreement between the two datasets is good in terms of mean PBL height, especially over sea. The CHAMP data show the major features of PBL height with a realistic transition from stratocumulus regions to shallow and deep cumulus areas. CHAMP also shows a substantial amount of PBL height variability that might proof useful to study PBL dynamics.

\section{Introduction}

Since the 1850s when C. Piazzi-Smyth found the trade-wind inversion by measuring the temperature while climbing the peaks of Tenerife of the Canary Islands, the trade-wind inversion has been at the center of many research efforts in tropical and sub-tropical meteorology. Several campaigns followed these initial measurements. The work of [vF36] has helped to establish the trade-wind inversion as an ubiquitous part of the Hadley circulation and the tropical climate.

Recently scientist have become aware of just how important the dynamics of PBL inversions is to the overall climate system, e.g. [MMRA96, $\mathrm{PGH}^{+}$96]. 
The sub-tropics are the regions of the globe where persistent sheets of Stratocumulus (Sc) clouds cool the planet by reflecting a substantial portion of the downwelling shortwave radiation. The regions of the world where the cloud radiative forcing is largest are the ones associated with stratocumulus off the west coasts of continents. The amount of clouds in the sub-tropics is highly correlated with the PBL depth (the height of the PBL inversion). Shallower boundary layers are associated with larger cloud cover due to a moister PBL. Deeper boundary layers are associated with trade-wind cumulus and smaller values of cloud cover.

How the transition from shallower PBLs with Sc to deeper PBLs with cumulus happens, and the physical mechanisms involved is still a matter of research, although significant progress has been achieved during the last twenty years. Much of this progress has been achieved through a successful combination of theory and intensive observational campaigns in the sub-tropics (ASTEX, FIRE, DYCOMS), see e.g. [AKST04]. But unfortunately, these experiments are always localized in space and time and do not provide a realistic global picture.

Satellite remote sensing in the visible and infrared has been relatively successful in measuring variables associated with clouds. However, direct measurements of the PBL inversion characteristics have been difficult to achieve mainly due to limited vertical resolution. Although recently some preliminary efforts have been made using AIRS data to study PBL inversions [FTOF04].

Radio occultation (RO) offers a promising alternative for global PBL inversion measurements. Probing of the PBL using RO instruments has already been discussed in e.g. $\left[\mathrm{HAI}^{+} 04\right]$ based on the signal reappearance after entering the PBL. In this study we use the lowest altitude sampled by CHAMP $\left[\mathrm{WSB}^{+} 04\right]$ to derive the PBL height. We analyze these results by comparing them to values of the PBL height obtained from ECMWF data. A similar version of this article has also been published with Geophysical Research Letters [vETWB05].

\section{Data Processing}

The used ECMWF global analysis cover the years 2002/2003. They have a $1.5^{\circ}$ resolution and 60 vertical levels (about 18 levels between $0 \mathrm{~km}$ and $3 \mathrm{~km}$ ). ECMWF fields show generally good agreement with the PBL altitude as seen in radiosonde data [vENT03, vET04]. The top of the PBL in the ECMWF dataset was derived by finding at each gridpoint the altitude where the decrease of relative humidity with height is largest, under the constraint that the temperature is above $273 \mathrm{~K}$. This approach is a typical one for the determination of the sub-tropical PBL top [BB92].

The used CHAMP data was processed with the Full Spectrum Inversion (FSI) technique [JLBN03] at the GeoForschungsZentrum Potsdam, Germany. Processing is stopped when the FSI amplitude of an occultation is reduced by 
$50 \%$. This threshold has been derived by a quality check (bias and standard deviation with respect to other available data and simulations) of CHAMP data and thus independently from the PBL top altitude. Here we use offline produced CHAMP data, for the operational data stream several quality checks are additionally implemented leading to slightly higher altitudes for the cutoff.

The global impact of the FSI threshold setting on the data quality is shown for a subset of profiles in Figure 1. Threshold settings corresponding to an amplitude reduction by $30 \%$ (factor 0.3 ) and $70 \%$ (factor 0.7 ) are compared to the operational setting of 0.5 . Refractivity standard deviation and bias are calculated with respect to the above mentioned ECMWF data at the mean location of the observation. The more conservative the threshold, the better the data quality but the lower the penetration into the lower atmospheric layers. A factor of 0.5 still allows a significant proportion of profiles entering the lowest $2 \mathrm{~km}$.
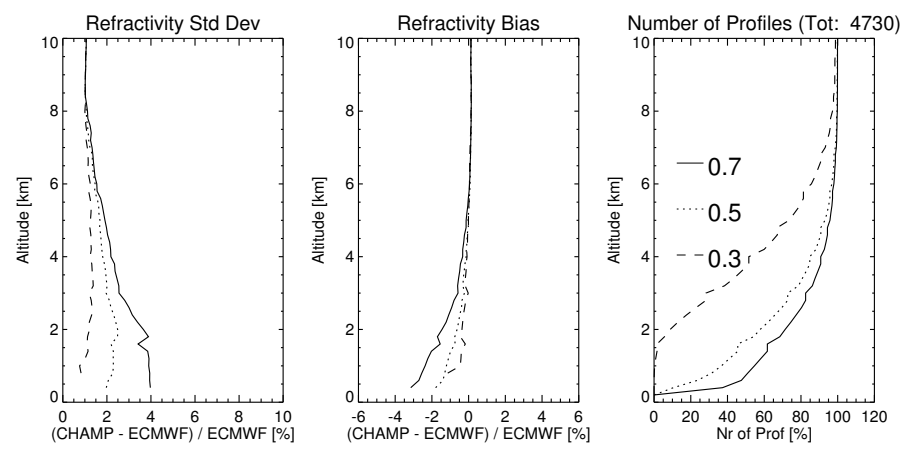

Fig. 1. Standard deviation (left) and bias (middle) of CHAMP profiles processed with different FSI threshold settings. Occultations are compared to co-located ECMWF profiles. Number of profiles is shown on the right.

A further comparison of the PBL top altitude and the 0.5 FSI amplitude threshold settings based on simulations in shown in [vETWB05]. Note that our PBL detection is independent on the actual quality of the refractivity profiles since it uses the FSI amplitude. It only requires that the measurement penetrates down to the PBL top.

In total there are 109641 occultations available for the years $2002 / 03$, out of which we removed about 20000 that terminated above $3 \mathrm{~km}$. This step was introduced since the PBL is usually below $3 \mathrm{~km}$ and the ECMWF resolution is only able to capture PBL inversions up to about $2.5 \mathrm{~km}$ [vET04]. In total, 87598 occultations were left (38879 over land). CHAMP does measure also within the PBL, although here we assume that the majority of the measurements is terminated by the PBL top. This is caused by the refractivity gradient present at the PBL, where the decreasing humidity and possible clouds along 
with radiative and evaporative cooling contribute to the gradient. Although it is in general possible to use this changing refractivity gradient to identify the PBL top in ECMWF data, the use of a relative humidity change proves more robust and was thus applied here.

Note that the presented results depend on the tracking algorithm used onboard the receiver. Software updates to the tracking algorithm will modify the relation of the PBL top to the lowest altitude sampled by CHAMP, in particular the open loop implementation will probe more frequently into the PBL [Sok01].

\section{Results}

Figure 2 shows the mean CHAMP and ECMWF PBL altitude above the Earth surface. On average, about 33 measurements enter each grid box. Both plots show similar features, especially over the Ocean. Mean altitudes around $0 \mathrm{~km}$ are found for polar latitudes. Also visible is the gradual increase in PBL height when moving from polar latitudes toward the equator.
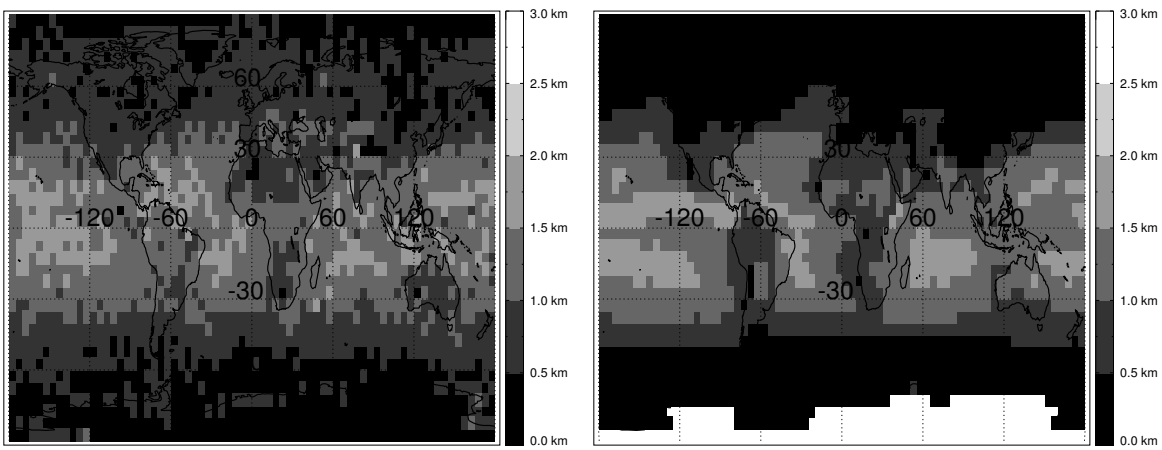

Fig. 2. Left: Mean minimum altitude found in CHAMP data. Right: Mean altitude of minimum relative humidity gradient calculated from ECMWF data. Data is averaged over a $5^{\circ}$ latitude longitude grid. White areas indicate that temperatures were never above $273 \mathrm{~K}$.

In particular over the sub-tropics and tropics, the transition from a shallow stratocumulus PBL close to the west coasts, to a deeper cumulus PBL $\left[\mathrm{DJC}^{+} 99, \mathrm{SAA}^{+} 01, \mathrm{~S}^{+} 03\right]$, is visible in both datasets. Although it is clear that in the Sc regions ECMWF gives values that are consistently lower. In the deep tropics the two datasets diverge in some regions: 1. In the Eastern Pacific, around $10 \mathrm{~N}$, the ECMWF data shows a peak value for the PBL height that presumably corresponds to the inter-tropical convergence zone (ITCZ); 2. In the Western Pacific, a maximum is apparent in CHAMP at around 10-15 N. 
Although there are differences between CHAMP and ECMWF, the subtropical PBL evolution is captured relatively well by the CHAMP data. For example the transition in PBL height from the coast of California to Hawaii and the equator is relatively similar in both datasets. In order to investigate such an evolution in some more detail, Figure 3 shows the mean PBL height along a cross-section from $35 \mathrm{~N}, 125 \mathrm{~W}$ to $1 \mathrm{~S}, 173 \mathrm{~W}$. This particular crosssection was chosen since it is able to represent the climatology of a typical transition from stratocumulus, to cumulus and then to deep convection, and is has been used before in intercomparison studies of the parameterizations in atmospheric models $\left[\mathrm{S}^{+} 04\right]$. An increase in PBL height in both data sets from about $1 \mathrm{~km}$ at $30 \mathrm{~N}$, to about $2 \mathrm{~km}$ south of $15 \mathrm{~N}$ is found. Also, the flatness of the curves in the tropics at about $2 \mathrm{~km}$ is found in both datasets. Close to the coast the two data sets diverge a little, possibly due to topography issues. Also shown in Figure 3 is the relatively large value of standard deviation (around $1 \mathrm{~km}$ ) of the CHAMP data set.

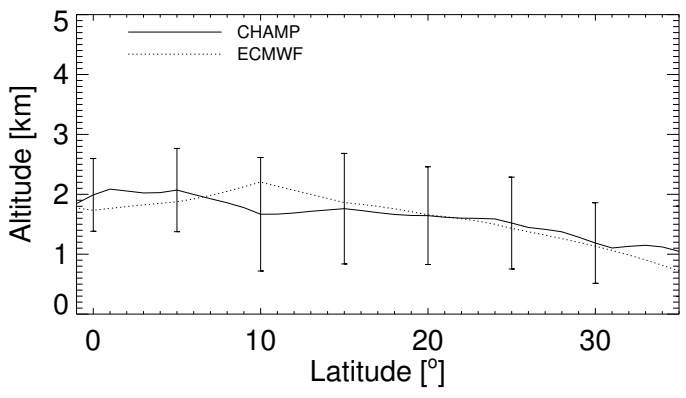

Fig. 3. Latitude altitude slice along $1 \mathrm{~S}, 173 \mathrm{~W}$ to $35 \mathrm{~N}, 125 \mathrm{~W}$ showing the mean PBL altitude from CHAMP data over a $5^{\circ}$ latitude longitude grid. Vertical lines indicate the error bars. Also shown is the altitude where the minimum gradient of relative humidity was found in ECMWF data.

In order to get some more insight in the PBL variability, Figure 4 shows the histograms (occurrence in absolute numbers of observations) of PBL height for three boxes along the previous cross-section for altitudes up to $4 \mathrm{~km}$.

In area $\mathrm{A}$, closer to the $\mathrm{Sc}$ regions, we find two peaks in the histogram: one in the first $400 \mathrm{~m}$ above the surface (surface, low stratus and stratocumulus) and another one between $1.6 \mathrm{~km}$ and $2 \mathrm{~km}$, with most of the observations in this range from the surface to $2 \mathrm{~km}$. In area $\mathrm{B}$, there is one dominant peak just above $2 \mathrm{~km}$, but also several occultations terminating near the surface. The two-peak nature of the histograms in this stratocumulus and cumulus regions seem to point to a situation where two dominant regimes alternate: 1.) a low stratocumulus regime or a weak inversion with occultations reaching the surface; 2.) a fully developed trade cumulus regime. In area $\mathrm{C}$, there is 

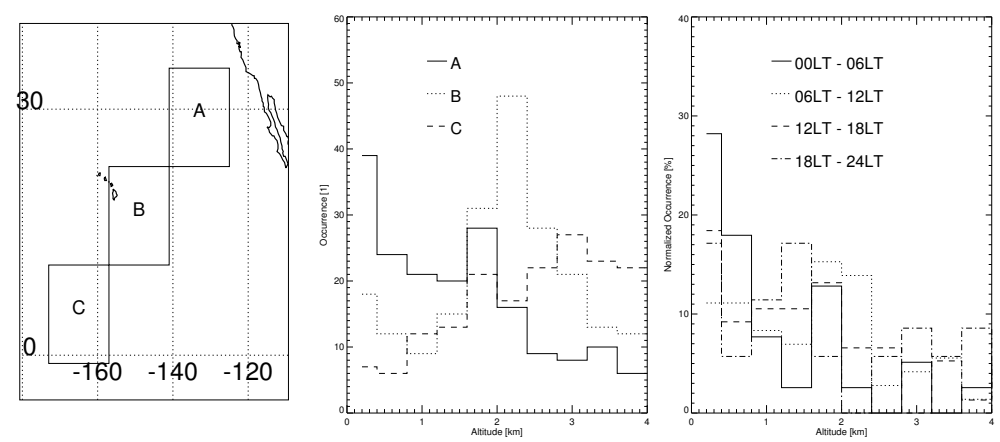

Fig. 4. Left: Map of Pacific Ocean and California showing 3 selected areas. Middle: Histogram of occultations reaching the given altitude in the selected area. Right: Histogram of normalized occurrence with respect to local time interval in area A. Bin size $0.4 \mathrm{~km}$.

only one flat peak between about $2.5 \mathrm{~km}$ and $3.5 \mathrm{~km}$ presumably associated with deep moist convection.

Also shown in Figure 4 is the normalized occurrence for four specific local time intervals in area $\mathrm{A}$. The normalization is performed with respect to the local time interval since the coverage is not uniform (moving from 00LT to 24LT through the intervals there are 39, 72, 76, 35 occultations) and thus one should be cautious when interpreting the data. Although some features can identified: 1) At any time of the day there are always two peaks, one close to the surface and the other somewhere between $1 \mathrm{~km}$ and $2 \mathrm{~km} ; 2$ ) During local night and early morning (00LT-06LT), when stratus and stratocumulus are deeper and more frequent due to a strong cloud top longwave cooling driving convection, there are more observations closer to the surface than close to $2 \mathrm{~km} ; 3)$ During local morning and noon (06LT-12LT) on the other hand, the most populated peak is closer to $2 \mathrm{~km}$, with values close to the surface about one-third smaller than during the previous period. These features agree with what would be expected from previous studies. In fact, if the quasi-bimodal structure that is found in area A is actually reflecting the prominence of two specific regimes of the boundary layer, namely a low stratus/stratocumulus regime and cumulus regime, then the diurnal cycle results may well reflect the higher frequency of occurrence of stratus during local night and cumulus during local daytime.

\section{Conclusion}

We use FSI processed CHAMP RO data for the years 2002 and 2003 to estimate the PBL height. We use a simple approach by assuming that the lowest altitude sampled by the CHAMP instrument is representative of the PBL height. This altitude is compared to ECMWF analysis data for the same 
period. The top of the PBL in ECMWF data is calculated as the altitude where the gradient of relative humidity with respect to height shows its minimum. Maps of mean PBL height show good agreement between CHAMP and ECMWF, in particular over the Ocean. The transition in mean PBL height from the stratocumulus regions to the cumulus and deep cumulus areas is well captured by the CHAMP data. Moreover, the CHAMP data exhibits a fair amount of variability in PBL height. Although this variability looks reasonable it is still unclear how much of it is actually representing the dynamics of the PBL height.

This and other issues will need to be investigated further in order to precisely define the usefulness of the CHAMP data set as an instrument to understand the dynamics of the PBL height in a global perspective. Future work will also focus on more sophisticated algorithms to derive the PBL height from RO data and on how to use the amplitude to derive further information such as inversion depth. It is anticipated that this data could be assimilated into weather prediction models.

Acknowledgments

A. von Engeln was partly funded by the German Federal Ministry of Education and Research (BMBF), within the AFO2000 project UTH-MOS (Grant 07ATC04), and during his visit at the Naval Research Laboratory, Monterey, USA by the Visitor Support Program of the Office of Naval Research International Field Office in London (Grant Number: N00014-04-1-4020). J. Teixeira acknowledges the support of the Office of Naval Research under Program Element 062345N. The authors would like to thank G. Beyerle (GeoForschungsZentrum Potsdam, Germany) for software development and data processing.

\section{References}

[AKST04] A.S. Ackerman, M.P. Kirkpatrick, D.E. Stevens, and O.B. Toon. The impact of humidity above stratiform clouds on indirect aerosol climate forcing. Nature, 432:1014 - 1017, 2004.

[BB92] A.C.M. Beljaars and A.K. Betts. Validation of the boundary layer representation in the ECMWF model. ECMWF Seminar Proc. Validation of models over Europe, ECMWF, Reading, United Kingdom, 1992.

$\left[\mathrm{DJC}^{+}\right.$99] P.G. Duynkerke, P.J. Jonker, A. Chlond, M.C. Van Zanten, J. Cuxart, P. Clark, E. Sanchez, G. Martin, G. Lenderink, and J. Teixeira. Intercomparison of three- and one-dimensional model simulations and aircraft observations of stratocumulus. Bound.-Layer Meteor., 92(3):453487, 1999.

[FTOF04] E.J. Fetzer, J. Teixeira, E.T. Olsen, and E.F. Fishbein. Satellite remote sounding of atmospheric boundary layer temperature inversions over the subtropical eastern pacific. Geophys. Res. Lett., 31(17), 2004.

$\left[\mathrm{HAI}^{+} 04\right]$ G.A. Hajj, C.O. Ao, B.A. Iijima, D. Kuang, E.R. Kursinski, A.J. Mannucci, T.K. Meehan, L.J. Romans, M. de la Torre Juarez, and T.P. Yunck. CHAMP and SAC-C atmospheric occultation results and intercomparisons. J. Geophys. Res., 109, 2004.

[JLBN03] A.S. Jensen, M.S. Lohmann, H.H. Benzon, and A.S. Nielsen. Full spectrum inversion of radio occultation signals. Radio Sci., 38(3):6-1 -6-15, 2003. 
[MMRA96] C.-C. Ma, C.R. Mechoso, A.W. Robertson, and A. Arakawa. Peruvian stratus clouds and the tropical pacific circulation: a coupled oceanatmosphere GCM study. J. Climate, 9(7):1635-1645, 1996.

$\left[\mathrm{PGH}^{+}\right.$96] S.G. Philander, D. Gu, D. Halpern, G. Lambert, N.-C. Lau, T. Li, and R.C. Pacanowski. Why the ITCZ is mostly north of the equator. J. Climate, 9(12):2958-2972, 1996.

$\left[\mathrm{S}^{+} 03\right] \quad$ A.P. Siebesma et al. A large eddy simulation intercomparison study of shallow cumulus convection. J. Atmos. Sci., 60(10):1201-1219, 2003.

$\left[\mathrm{S}^{+} 04\right] \quad$ A.P. Siebesma et al. Cloud representation in general circulation models over the northern pacific ocean: A EUROCS intercomparison study. Quart. J. Roy. Meteor. Soc., 130(604):3245-3267, 2004.

$\left[\mathrm{SAA}^{+} 01\right]$ B. Stevens, A.S. Ackerman, B.A. Albrecht, A.R. Brown, A. Chlond, J. Cuxart, P.G. Duynkerke, D.C. Lewellen, M.K. Macvean, R.A.J. Neggers, E. Sanchez E, A.P. Siebesma, and DE Stevens. Simulations of trade wind cumuli under a strong inversion. J. Atmos. Sci., 58(14):1870-1891, 2001.

[Sok01] S. Sokolovskiy. Tracking tropospheric radio occultation signals from low Earth orbit. Radio Sci., 36(3):483-498, 2001.

[vENT03] A. von Engeln, G. Nedoluha, and J. Teixeira. An analysis of the frequency and distribution of ducting events in simulated radio occultation measurements based on ECMWF fields. J. Geophys. Res., 108(D21):ACL 3-1 to ACL 3-12, 2003.

[vET04] A. von Engeln and J. Teixeira. A ducting climatology derived from ECMWF global analysis fields. J. Geophys. Res., 109, 2004.

[vETWB05] A. von Engeln, J. Teixeira, J. Wickert, and S. A. Buehler. Using champ radio occultation data to determine the top altitude of the planetary boundary layer. Geophys. Res. Lett., 32(6), 2005.

[vF36] H. von Ficker. Die Passatinversion. Veröffentlichungen Meteor. Institut, Universität Berlin, 1936. 33 pp.

$\left[\mathrm{WSB}^{+} 04\right]$ J. Wickert, T. Schmidt, G. Beyerle, R. König, Ch. Reigber, and N. Jakowski. The radio occultation experiment aboard CHAMP: Operational data analysis and validation of vertical atmospheric profiles. J. Meteorol. Soc. Jpn., 82(1B):381-395, 2004. 